\title{
Análise bioética da propaganda e publicidade de medicamentos
}

\author{
Bioethical analysis of drugs advertisement and publicity
}

\author{
M aria José D el gado Fagundes ${ }^{1}$ \\ M agnely Gomes Alves Soares ${ }^{2}$ \\ Nilza M aria Diniz ${ }^{3}$ \\ Jansen Ribeiro Pires ${ }^{4}$ \\ Volnei Garrafa ${ }^{4}$
}

${ }^{1}$ Anvisa - Agência Nacional de Vigilância Sanitária, Ministério da Saúdee CátedraUNESCO de Bioética da U niversidade de Brasília. Caixa postal 04451. 70904-970 Brasília DF. bioetica@unb.br ${ }^{2}$ Comissão Nacional de Ética em Pesquisa / M inistério da Saúde. ${ }^{3}$ Departamento deBiologia Geral, Universidade Estadual de Londrina. ${ }^{4}$ Cátedra UNESCO de Bioética da U niversidade de Brasília.
Abstract This study investigates how advertising campaigns for drugs influence drug prescription practices among physicians from a point of view of "protection ethics" and of "intervention bioethics". It also analyzes information quality in advertisements for prescription drugs before and after the AN VISA (N ational Agency for Sanitary Protection) RDC 102/200 Resolution wich regulates drugs advertising as well as discusses the regulating role of the state in this area. A first approach was to interview 50 physicians in Brasília/DF ( 25 general physicians and 25 surgeons) in order to examine how they perceive the effects of advertisement on their professional activities. A second approach was to study 10 publicity pieces, five from before and five from after the RDC Resolution. The results showed that: a) $98 \%$ of phsicians are visited by sales representatives on a regular basis; b) $86 \%$ of physicians receive gifts during these visits; c) $68 \%$ beleive that advertising strongly influences prescription practices; $d$ ) $14 \%$ related prescription practices to the receival of rewards; e) $68 \%$ beleive that information contained in advertisements is unreliable; f) before the RDC Resolution, $28 \%$ of advertisements had adequate information content (counter-indications, indications precautions, warnings, and adverse reactions); after the RDC Resolution, that number grew to $79 \%$.

Key words Drug advertising and publicity, Legislation, Bioethics
Resumo Sob a perspectiva da "ética da prote ção" e da "bioética de intervenção", a pesquisa analisa a influência das peças publicitárias demedicamentos vei culadasà classe médica na prescrição de medicamentos. Estuda, ainda, a qualidade das informações nas propagan das demedicamentos de venda sob prescrição, antes e depois da $R e$ solução da Diretoria Colegiada da Anvisa - RDC 102/2000, que regulamenta a propaganda de me dicamentos no país, bem como discute o papel regulador do Estado na área. Primeiramente, foram entrevistados 50 médicos de Braśl lia, a fim deexaminar como percebem os efeitos da propaganda sobre sua atividade profissional. Em seguida, foram avaliadas 10 peças publicitárias, 5 veiculadasantes e 5 depois da RDC 102/2000. Os resultados permitiram concluir que: a) $98 \%$ dos médicos recebem visitas regulares de representantes comerciais; b) $86 \%$ recebem brindes; c) $68 \%$ crêem na influência direta da propaganda sobre a prescrição; d) $14 \%$ disseram prescrever medicamentos em função do recebimento de prêmios; e) $68 \%$ acreditam existir inverdades nas informaç̧ões das peças publicitárias; $f$ ) antes da RDC, as informações (contra-indicações, indicações, precauções, cuidados e advertência) nas propagandas representava $28 \%$ dos casos; após a RDC, foram encontradas informações em $79 \%$ dos casos. Palavras-chave Propaganda e publicidade de medicamentos, Legislação, Bioética 
Introdução

A publicidade de medicamentos define padrões de mercado e de comportamento das pessoas, exercendo impacto concreto sobre as práticas terapêuticas. N este sentido, a preocupação com a qualidade da informação sobre medicamentos deve fazer parte do cotidiano de profissionais de saúde e dos consumidores ${ }^{1}$.

0 apelo ao consumo e bens de serviços e a estratégia de ligar este consumo ao desfrute (real ou fictício) debem-estar, saúdeefelicidadeéuma das características da sociedade moderna, onde a "mercadoria medicamento" éuma unidadeque possui "valor de uso" ao lado do "valor de troca", e que, a exemplo das demais mercadorias, se transforma em instrumento de acumulação de poder e capital ${ }^{2}$.

Vários estudos mostram que a propaganda consegue realmente alterar o padrão de prescrição dos médicos s $^{3,45,5,6,7}$. Considerando a ocorrência desse fenômeno sobre as práticas terapêuticas, esperar-se-ia que o material de propaganda de medicamentos tivesse boa qualidade, fornecendo informações importantes e confiáveis sobre 0 produto anunciado 8 .

Em vista da crescente veiculação de campanhas publicitárias de medicamentos sem ferramentas eficazes de controle sobre a veracidade das informações - seja na forma de divulgação, promoção e comercialização, pela imprensa falada ou escrita e, modernamente, via internet - e as recomendações da Comissão Parlamentar de Inquérito sobre M edicamentos instalada há algum tempo no Congresso Nacional, a Agência Nacional de Vigilância Sanitária (Anvisa) elaborou uma norma específica com os critérios para a publicidade de medicamentos - a denominada Resolução da Diretoria Colegiada RDC no 102/00, de 30/11/2000.

A referida norma instrumentalizou a fiscalização sobre informações transmitidas pelas propagandas de medicamentos no Brasil. Esse controle é eticamente defensável, uma vez que, em questões básicas como a saúde pública, o Estado deve tomar a frente e intervir, no compromisso de proteger a população contra qualquer possibilidade de ação que venha causar-Ihe danos ${ }^{9}$, ou seja, intervir frente ao iminente risco sanitário que o consumo descontrolado de medicamentos representa.

\section{Marco referencial}

O uso de medicamentos éum indicador indireto da qualidade dos serviços de saúde e da propaganda dirigida a médicos e população. Pode ser utilizado para identificar necessidades de intervenções como na educação da população, subsidiar a elaboração de políticas públicas, conter a divulgação, venda e consumo demedicamentos ${ }^{8}$.

Um estudo feito por Barros ${ }^{10}$ comparou as informações disponíveis no Dicionário de Especialidade Farmacêutica (DEF) para os produtos campeões de vendas, com aqueles presentes no Physician's Desk Reference (PDR) e no Drug Information for the Health CareProfessional (USPDI), onde se verificaram discrepâncias significativas particularmente no que diz respeito às reações adversas, contra-indicações einterações. N o DEF não constavam, mais freqüentemente, alusão aos efeitos adversos e mecanismos de ação, inexistentes em $50 \%$ dos produtos avaliados. Esse comportamento, considerando que quase todos os produtos são fabricados pelas mesmas empresas (multinacionais), corrobora a idéia deque há um duplo padrão de conduta dos fabricantes, conforme o país ou de acordo com a exigência ou não de maior rigor na regulamentação existente ou no grau de cumprimento efetivo da mesma.

A realidadelatino-americana exige uma perspectiva de pensamento que contemple a necessidade de proteção dos vulneráveis; uma proposta que justifique ações concretas do Estado. N este sentido, a chamada "bioética deintervenção" vem sendo desenvolvida desde o final da década passada no sentido de buscar relacionar essa disciplina com as distorções sociais, econômicas, educacionais e de saúde pública pelas quais passam as nações periféricas, em especial na América Latina ${ }^{11}$. A bioética deintervenção, preconizada por Garrafae Porto ${ }^{12}$, parte do referencial conseqüencial ista de conotação utilitarista, sustentado principalmente nas teorias filosóficas de Jeremy Bentham e John Stuart Mill, de que as decisões e políticas sanitárias públicas e de cunho social eticamente adequadas são aquelas que atendem ao maior número de pessoas, pelo maior espaço de tempo possível equeresultem nas mel hores conseqüências coletivas.

Esse posicionamento confronta com as tradicionais abordagen s bioéticas de conotação anglosaxônica, queprivilegiam os interesses individuais em detrimento daqueles que dizem respeito às maiorias populacionais. D entro desse panorama, o que se discute na bioética de intervenção são 
ações preferencialmente públicas e coletivas, que possam ser tomadas para minimizar as diferentes situações de vulnerabilidade. Assim, a bioética de intervenção apresenta propostas efetivas para fazer valer os direitos das populações marginalizadas pelo seu estado de pobreza e exclusão, pelas dificuldades de acesso aos serviços de saúde, pelo abandono social associado à excessiva concentração de renda e de restrições de suas liberdades primárias, que caracterizam a estratificação social dos países periféricos.

É indispensável ressaltar, no entanto, que a bioética de intervenção não se deixa aprisionar pelo utilitarismo clássico, procurando equilibrar ações e conseqüências eminentemente práticas com o campo do humanismo. Daí surge a proposição deum novo "utilitarismo solidário", aqui entendido como uma fusão entre o conceito de solidariedade crítica desenvolvido por Selli \& Garrafa $^{13}$ e a visão original da proposta de bioética de intervenção, que remete as decisões a objetivos maximizadores para as políticas públicas de saúde. A interpretação do "utilitarismo solidário" implica comprometimento transformador com a alteridade, com o outro, além de requerer, também, uma resposta objetiva de parte desse outro, o que o diferencia sobremaneira do assistencialismo clássico e inorgânico.

Os medicamentos não são mercadorias que possam ser oferecidas da mesma maneira que outros bens e serviços passíveis de regras do livre mercado ${ }^{14}$. Nesta perspectiva, Sen ${ }^{15}$ adverte sobre os riscos inerentes à insistência de se manter o uso de abordagens mercadológicas que fazem a separação entre eficiência e ética. Para ele, esse modelo, ao invés de trazer ganhos, acaba esgotando as possibilidades de crescimento, por interferir justamente na variável quenão tem como ser controlada: a motivação humana. Por essa razão, defende uma economia fundamentada na ética, visando o bem-estar das pessoas.

Sass ${ }^{16}$, por sua vez, fala de uma vulnerabilidade quase intangível, que se manifesta pelas re lações interpessoais tipicamente caracterizadas pela frieza das transações comerciais cotidianas, nas quais os seres humanos são vistos apenas como potenciais compradores de produtos eserviços e, por isso mesmo, passíveis de serem seduzidos por uma nova embalagem, cores ou letras muito vistosas nos cartazes de divulgação e até mesmo "pelas doces palavras dos seus artistas preferidos que depõem a favor de determinada droga".

Kottow $^{17}$ já interpreta que tais práticas colocam as pessoas numa situação de "vulnerabilidade circunstancial" ou "secundária", cuja aná- lise pode ser feita sob duas perspectivas. A primeira, mais teórica, discute sobre seus pressupostos e implicações sociais; e a segunda, mais engajada na busca de soluções práticas, desloca seu eixo em direção a um maior comprometimento por meio de ações afirmativas, à semeIhança do que defende a proposta de bioética de intervenção. Esse autor considera que, embora todos os seres humanos sejam antropologicamente vulneráveis (vulnerabilidade primária), a sociedade, de al guma forma, cria meios capazes de protegê-los; no entanto, somente os destituídos, aqueles mais suscetíveis de sofrerem danos, padecem de "vulnerabilidade circunstancial" ou "secundária".

N essas situações assimétricas, éperfeitamente justificável, sob o ponto de vista moral, o papel controlador e regulador do Estado - que Schramm ${ }^{18}$ desenvolve teoricamente com o que denomina de "ética da proteção", objetivando defender aqueles segmentos mais frágeis e menos informados da população. N esse sentido, a Anvisa, agência estatal, assumiu sua responsabilidade com relação à regulamentação da publicidade de medicamentos a partir do ano 2000. Questões referentes à propaganda - tais como, tamanho e espaçamento das letras, composição do produto, precauções, posologia etc. - ligadas à questão de proteção da saúde dos indivíduos, encontram-secontempladasna RDC 102/00. Essa regulamentação, concretamente interventiva e protetora da cidadania, é el emento minimizador da "vulnerabilidadecircunstancial" verificada na população brasileira.

A preocupação com a qualidade dos produtos farmacêuticos é uma constante nos órgãos sanitários dos países democráticos. As agências governamentais são responsáveis pela definição dos parâmetros de qualidade e pela fiscalização do seu cumprimento. É obrigação da indústria cumprir rigorosamente as regulamentações referentes à qualidade e segurança de seus produtos, bem como divulgar informações quetenham por objetivo a correta orientação de seu uso para preservar a saúde dos consumidores ${ }^{19}$.

Aos argumentos sobre a necessidade de proteção e intervenção do Estado, acrescentam-se os prejuízos que a população sofre com propagandas enganosas, abusivas e incompletas. Entre os prejuízos diretos, destacam-se o agravamento das situações de saúde e o dano financeiro causado pela aquisição de produtos ineficazes ou inadequados. Quanto aos danos indiretos, podem ser lembrados os recursos gastos pelo Estado para curar doenças agravadas, intensifi- 
cadas pelas facilidades de acesso ao medicamento e pelo poder persuasivo da propaganda ${ }^{20}$.

Assim, no caso particular da fiscalização sobre a propaganda de medicamentos, que é tema de discussão ética, a participação e o controle social adquirem importância fundamental por estarem inseridos no contexto da cidadania. 0 presente trabalho, portanto, teve como objetivo avaliar as estratégias de propaganda utilizadas pelos laboratórios e dirigidas aos médicos, além de analisar a qualidade das informações contidas nas propagandas de medicamentos de venda sob prescrição direcionada à classe médica, antes edepois da publicação dajá mencionada Resolução emitida pela Anvisa.

\section{Métodos}

Esse trabalho foi desenvolvido em duas etapas. Na primeira, por meio da aplicação de questionários, se procurou ouvir a classe médica sobre a publicidade de medicamentos. 0 instrumento de pesquisa foi elaborado de maneira a identificar aspectos relacionados à visita de propagandistas aos consultórios médicos, tais como o teor do conteúdo das propagandas, a forma como esses abordam a classe médica e quais as opiniões dos profissionais sobre essa abordagem. 0 questionário utilizado foi composto por dez questões, nove de múltipla escolha e uma questão aberta, aplicado a 50 médicos, escolhidos aleatoriamente em hospitais públicos de atenção terciária de Brasília, Distrito Federal, Brasil, sendo 25 clínicose 25 cirurgiões. A opção em dividir as categorias dos profissionais mé dicos, com práticas específicas distintas, teve como proposta a avaliação do comportamento das mesmas diante das estratégias promocionais da indústria farmacêutica.

A segunda etapa constou de uma análise de informações contidas em peças publicitárias de medicamentos sob prescrição, veiculadas antes e depois da publicação da RDC Anvisa 102/00. Foram estudadas cinco peças publicitárias veiculadas antes da publicação da referida Resolução e cinco outras veiculadas depois, procurando-se identificar as diferenças existentes entre elas, assim como o risco sanitário que apresentavam. É importante salientar que as cinco peças publicitárias vei culadas antes da publicação da RDC não foram as mesmas veiculadas de pois da vigência dessa Resolução. Isto ocorreu devido à não continuidade da publicidade desses medicamentos, ao mesmo tempo em que a introdução de novos fármacos no mercado promoveu a veiculação de outras propagandas. Os critérios para inclusão e exclusão das peças para o estudo, além da categoria terapêutica, foram estabelecidos a partir da maior ocorrência no número de autos de infração, o que possibilitou a oficialidade do dado uma vez que a Agência Reguladora já havia implementado a ação fiscalizadora cabível para aqueles produtos no período de janeiro a junho de 2003.

A pesquisa foi devidamente aprovada pelo ComitêdeÉtica em Pesquisa da Secretaria deSaúde do Distrito Federal.

\section{Resultadosediscussão}

\section{Entrevistas}

Dos 50 médicos entrevistados na primeira etapa do estudo, 36 eram homens e 14 mulheres, 25 eram clínicos e 25 cirurgiões. Os resultados obtidos com a aplicação do questionário foram os seguintes. Quando perguntados se recebiam visitas de propagandistas da indústria farmacêutica, $98 \%$ dos médicos confirmaram receber essas visitas. Em relação à freqüência com que as visitas ocorriam, $40 \%$ dos entrevistados disseram recebêlas semanalmente, $22 \%$ mensalmente, $12 \%$ diariamente, $10 \%$ a cada três dias e $16 \%$ mencionaram outras freqüências. Já $45 \%$ dos sujeitos da amostra alegaram receber visitas de diferentes propagandistas que divulgavam um mesmo produto. É importantesalientar que $86 \%$ dos entrevistados afirmaram receber brindes durante as visitas.

Quando questionados sobre a prescrição dos medicamentos, a maioria afirmou não ser influenciada pela publicidade. Contudo, 14\% dos médicos entrevistados disseram prescrevêlos em função do recebimento de prêmios. No que tange à opinião sobre a influência da propaganda na prescrição de medicamentos, $68 \%$ acreditam existir uma influência direta da propaganda sobre a prescrição, $24 \%$ disseram que não há qualquer influência e $8 \%$ não têm opinião formada. Foi observado, ainda, que $68 \%$ acreditam haver inverdades ou incorreções nas peças publicitárias, $22 \%$ dos médicos confiam plenamente nas informações recebidas e 10\% não têm opinião formada. Finalmente, no que se refere à distribuição de folhetos de propaganda destinados aos pacientes, $28 \%$ dos médicos afirmaram receber esse tipo de material dos propagandistas. 


\section{Peças publicitárias}

Com relação à segunda etapa da pesquisa, foram analisadas as peças publicitárias de 10 medicamentos divididos em dois grupos. 0 primeiro grupo trata de 5 peças publicadas antes da vigência da RDC102/00 (um medicamento para emagrecimento ou $A_{1}$; um antidepressivo ou $A_{2}$ ; um medicamento para controle de colesterol ou $A_{3}$; além de dois antibióticos ou $A_{4}$ e $A_{5}$ respectivamente) e 5 outras publicadas depois (um medicamento contra impotência sexual ou $D_{i}$; a "pílula do dia seguinte" ou $D_{2}$; um outro indicado para aumentar o nível de HDL colesterol em pacientes com hipercolesterolemia primária, hiperlipidemia combinada e pacientes pós-infarto do miocárdio ou $\mathrm{D}_{3}$; um antibiótico ou $\mathrm{D}_{4}$; eum ansiolítico ou $\mathrm{D}_{5}$ ).

\section{a) Grupo de medicamentos I}

No primeiro grupo, todas as peças analisadas foram veiculadas em revistas direcionadas à classe médica e para profissionais desaúde, entreos anos de 1994 e 1996. Na análise do material, percebe-se claramente 0 estímulo à prescrição e ao uso do medicamento por meio da utilização de frases, imagens, ausência de informações completas e de afirmações sem comprovação científica, demonstrando evidente apelo mercadológico.

$A$ peça do medicamento $A_{1}$, produto para emagrecimento, trazia como propaganda a frase "emagrecer com segurança", ilustrada com a embalagem do medicamento cercada de frutas. A referida peça não alertava sobre efeitos adversos do princípio ativo que poderia causar diminuição da pressão arterial e depressão do sistema nervoso central. 0 uso desseanorexígeno foi proibido dois anos mais tarde, o que demonstra a contradição com a segurança prometida pela peça publicitária.

A peça do medicamento $A_{2}$, ou seja, um antidepressivo sujeito a controleespecial, por sua vez, teve sua publicidade direcionada às farmácias com a peça publicitária lançando mão do seguinte argumento: "farmacêutico quetem ' $X$ ' nas prateleiras não fica deprimido na hora de ver os lucros", o que não inclui qualquer informação sobre o medicamento, a não ser que se tratava de um antidepressivo. Além disso, a publicidadeincluía a expressão "o antidepressivo eficaz e bem tolerado", sugerindo menos risco.

Poucos meses antes da publicação da Lei №. 9.294/96, que trata de propagandas impróprias e que deu base para a elaboração da RDC 102/00, a publicidade do medicamento $A_{3}$, utilizado para controle do colesterol, foi realizada com uma peça que apresentava irregularidades, mas que incluía o resumo da bula com as informações exigidas pela legislação. As frases: "aprovado pelo FDA" e "reduz o LDL-colesterol de maneira eficaz, segura e com menor custo para o paciente", continuavam enaltecendo o produto e as informações (contra-indicação, cuidados eadvertências), ainda que presentes, não receberam o destaque merecido.

A publicidade do medicamento $A_{4^{\prime}}$ um dos dois antibióticos estudados, trazia como mensagem: "novo padrão no tratamento das cistites". A ênfase, nesse caso, é dada à posologia "dois comprimidos em um único dia resolvem o problema de uma vez por todas". O corre que a peça não informava a dosagem de cada comprimido, o que dificultava a prescrição, além de não incluir informação referenteàs contra-indicações e cuidados.

Finalmente, a peça publicitária do produto $A_{5}$ um antibiótico de amplo espectro de ação, foi anunciada como "a verdadeira primeira escolha para infecções respiratórias". Além disso, há outras afirmações como "saboroso - inigualável sabor detutti-fruti" e "amoxicilina original recomendada pela OM S". Uma vez mais, as contra-indicações, cuidados eadvertências são excluídas do texto de apresentação do referido medicamento.

\section{b) Grupo de medicamentos II}

As cinco peças publicitárias integrantes do segundo grupo da pesquisa e veiculadas após a vigência da RDC 102/00 foram objeto de Autos de Infração instaurados pela Anvisa, no período de janeiro a junho de 2003. Uma característica que chamou atenção foi que a maioria das peças avaliadas apresentava dados como: contra-indicações, cuidados, advertências, interações medicamentosas, reações adversas. Convém ressaltar, no entanto, que tudo isso foi realizado exclusivamente por exigência legal e não com o real intuito de alertar o leitor/consumidor sobre os riscos do uso do medicamento. M egginson, M osley e Pietri ${ }^{21}$ advertem que, "há uma grande diferença entre agir legalmente - seguindo a letra da lei - e agir com ética e preocupação social". Os perigos, ao contrário do que seria esperado, aparecem sem o menor destaque e se perdem frente à exploração da suposta superioridade de um produto sobre outro, dando informações inverídicas uma vez que não apresentavam qualquer referência de comprovações científicas. Embora essas peças publicitárias tenham sido elaboradas depois da vigência da RDC 102/00, o caráter mer- 
cadológico ainda predomina até os dias atuais, 0 que leva à necessidade de reavaliar a legislação vigente.

A propaganda demedicamentos devenda sob prescrição, que deveria ser direcionada para a classe médica, portanto, é veiculada e direcionada maciçamente para o público leigo, nos mais diversos meios de comunicação. A publicidade do medicamento $D_{1}$, contra impotência sexual, por exemplo, foi realizada no site da "Universo On Line", contrariando a legislação uma vez que veiculava para público leigo a publicidade de medicamentos de venda sob prescrição médica. Esse é um exemplo de promoção que encobre a publicidade, por fazer parte do conteúdo editorial; a matéria informa sobre o "super $X$ ", a nova apresentação do medicamento com dosagem dobrada.

Num jornal de Brasília, a peça publicitária do medicamento $D_{2}$ foi veiculada na forma de matéria "[...] se a mulher não tiver acesso à pílula do dia seguinte, ela pode lançar mão do anticoncepcional normal, ingerindo todos os dias [...]", estratégia publicitária semel hante ao comentado anteriormente.

Ainda dentro da mesma análise, a peça publicitária do medicamento $D_{3}$ indicado para aumentar o nível de HDL colesterol, foi veiculada ao público não incluindo algumas informações básicas, tais como o número de registro, indicações, contra-indicações, cuidados, advertências e posologia. A peça também não incluía a sua classificação.

Da mesma forma, a peça publicitária do me dicamento $D_{4}$ indicado para o combate às infecções bacterianas, foi divulgado sem o devido registro no órgão governamental responsável, suprimindo também os cuidados, advertências, contra-indicações e a classificação do medicamento em relação à prescrição. Além disso, fazia comparações en tre essee outros medicamentos, utilizando como referência estudos não comparativos.

Por fim, a peça publicitária do medicamento $\mathrm{D}_{5}$, indicado para estados de ansiedade, foi apresentada sugerindo a diminuição de riscos ao afirmar o seguinte: "um ansiolítico sem risco de dependência". Esse medicamento apresentou também afirmações contraditórias que induziam ao erro ou confusão quanto à capacidade do indivíduo de operar máquinas após o consumo do medicamento, caso de frases como "não interfere na capacidade de dirigir ou operar máquinas perigosas", juntamente com outra que dizia "durante 0 tratamento, o paciente não deve dirigir veículos ou operar máquinas, pois suas habilidades e atenção podem estar prejudicadas". As informações, igualmente às situações anteriormente descritas, encontravam-sedesvinculadas decomprovação científica.

Em resumo, antes da vigência da RDC 102/ 00 , as peças publicitárias apresentavam informações imprecisas e tendenciosas. Esse fato pode ser constatado nas ilustrações inadequadas do medicamento $A_{1}$, na mensagem direcionada exclusivamente às farmácias na peça do medicamento $A_{2}$, na falta de destaque das informações mais importantes sobre o medicamento $A_{3}$ (embora tivesse o resumo da bula), na posologia inadequada do medicamento $A_{4}$ enas recomendações de uso do produto por uma respeitável instituição internacional de saúde e 0 sabor do medicamento $A_{5}$. Por outro lado, mesmo ocorrendo uma melhora da qualidade da informação pela vigência da RDC 102/00, observou-se que foram criadas novas formas de divulgação também inadequadas, tais como dosagens imprecisas, subtração de indicações, contra-indicações, cuidados, advertências, uso de comparações entre medicamentos sem base científica e atéa utilização da Internet em situações que ferem a legislação.

Portanto, apesar de algumas mudanças positivas já previstas no artigo 13 da RDC 102/2000, que restringe o público ao qual as peças de propaganda de medicamento de venda sob prescrição são dirigidas e estabelece os critérios para elaboração das mesmas, o caráter mercadológico ainda predomina no contexto brasileiro das propagandas de medicamentos. É urgente um esforço regulatório mais rígido eabrangente, que contribua para a diminuição do uso incorreto de medicamentos, a redução dos casos de reações adversas e dos índices de intoxicação humana².

A necessidade da formulação e implementação de regras que possam privilegiar os interesses da saúde pública, impondo limites à atuação do mercado farmacêutico, tem estado presente nos mais diferentes países, em especial nesseúltimo século, isto é, praticamente, desdea eclosão e consolidação da quimiosíntese industrial com a lógica de mercado a ela subjacente ${ }^{22}$. 0 Estado brasileiro, portanto, não pode fugir de assumir sua responsabilidade tanto no sentido de promover uma ética protetora que ben eficiea população, de acordo com o que apregoa Schramm ${ }^{18}$, como de atuar concretamente por meio de uma ética interventiva, quando o caso assim o requeira, como defendem Garrafa e Porto ${ }^{9,12}$.

Fica clara a necessidade de reavaliar a legisla- 
ção vigente, principalmente a propaganda de medicamentos de venda sob prescrição, que deveria ser direcionada exclusivamente para a classe médica, e que continua sendo dirigida pelas empresas para o público leigo, por meio das mais diversas mídias.

\section{Considerações finais econclusões}

0 papel regulador do Estado, com base na bioé tica de interven ção e visando a proteção da sociedade, deve ser continuamente exercido com relação à propaganda de medicamentos. A presente pesquisa constatou que, embora algumas mudanças legais tenham acontecido nos últimos anos, continuam ocorrendo irregularidades, em desacordo com a legislação vigente, influenciando a prescrição e o consumo de medicamentose, principalmente, induzindo as pessoas à automedicação.

Três estudos feitos respectivamente em Porto Alegre $^{23}$, Ponta Grossa ${ }^{20}$ e Brasília ${ }^{24}$ apresentam interessantes avaliações com relação à presença deinformações nas propagan das demedicamentos distribuídos para a classe médica. No trabaIho desenvolvido em Porto Alegre, $73 \%$ dos casos apresentavam posologia, o que é preocupante dado a importância da mesma; e $57 \%$ não apresentavam informações sobre precauções. N o trabalho de Ponta Grossa, foi observado que $66,2 \%$ das peças publicitárias não continham indicações, reações adversas ou efeitos colaterais. $\mathrm{Na}$ pesquisa de Brasília, os resultados da posologia não são muito diferentes dos encontrados em Porto Alegre, ou seja, apenas $65,6 \%$ apresentavam posologia; quanto aos dados relativos às contraindicações, advertências, reações adversas e precauções, estes se assemelhavam àqueles detectados em Ponta Grossa.

$M$ ais recentemente, a Anvisa ${ }^{25}$ realizou um amplo estudo sobre a informação contida nas propagandas de medicamentos destinada ao público leigo (na sua maioria) e constatou quea qualidade das informações nas peças publicitárias havia melhorado; houve quase que uma inversão na freqüência com relação às informações contidas nas peças publicitárias mostradas nos estudos anteriormente descritos, que oscilavam entre 75 a $80 \%$ delas.

Os resultados apresentados no presente estudo indicam que a classe médica sente-se influenciada pela propaganda de medicamentos, entre outras razões devido às insistentes visitas de propagandistas aos seus locais de trabalho. Essa prática pode ser analisada a partir da abordagem proposta por Fortes ${ }^{14}$, a qual condena que medicamentos sejam tratados como qualquer outro produto de consumo e que fiquem, portanto, suscetíveis às regras do livre mercado; os laboratórios farmacêuticos, nesses casos, estariam simplesmente tentando potencializar as vendas de seus produtos. De acordo com Sen ${ }^{15}$, essa conduta está na contra-mão de uma abordagem que procura promover o bem-estar das pessoas, pois seu enfoque principal privilegia as necessidades mercadológicas de consumo para determinado produto, contrapondo-se às considerações éticas que revelam os limites entre 0 que pode ser feito e o que é moral mente aceitável.

Quanto à distribuição de brindes, esse fato é uma flagrante infração ao artigo 18 da RDC102/ 00 que explicita ser proibido "oferecer ou prometer prêmios, vantagens pecuniárias ou em espécie, aos profissionais de saúde habilitados a prescrever ou dispensar medicamentos [...]". Oslaboratórios costumam oferecer prêmios para grupos de profissionais, como por exemplo, "coffee breaks" em seminários, bebedouros em hospitais e clínicas, inscrições em congressos. Tais prêmios não estão condicionados diretamenteà prescrição feita pelo médico; mas esse vínculo indireto acaba fazendo com que os prescritores criem "simpatia" pela empresa, o que indiretamente influencia na prescrição. 0 recebimento de prêmios em função da quantidade de prescrições feitas pelos médicos pode ser comparado à ideologia consumista identificada por Barros ${ }^{3}$, que critica a situação na qual a sociedade atual é movida pelo consumo desenfreado.

Quanto à confiabilidade das informações fornecidas pelos propagandistas, é preocupanteo fato de $22 \%$ dos médicos confiarem plenamente nas peças publicitárias distribuídas pelos laboratórios, principalmente por não haver embasamento em referências científicas na maioria delas; nesses casos, percebe-se um excesso de confiança dos prescritores de medicamentos nas propagandas. Sass ${ }^{16}$ entendequeesta prática induz a uma vulnerabilidade quase intangível das relações entre os atores envolvidos no processo, o que por sua vez coloca em risco a saúde da população. Essa maior probabilidade de os pacientes sofrerem danos poderia ser entendida também como de "vulnerabilidadecircunstancial", anteriormente definida ${ }^{17}$, pois embora os médicos envolvidos no processo tenham um certo grau de formação acadêmica, isto por si só não é suficiente para torná-los menos vulneráveis aos efeitos das propagan das e dos incentivos econômicos oferecidos pelos laborató- 
rios. Existem interações ideológicas da sociedade moderna de consumo que têm interferido nas ações das pessoas ${ }^{3}$, as quais não podem ser minimizadas no contexto dessa pesquisa.

As indústrias de medicamentos parecem estar mais preocupadas com suas vendas do que com a saúde pública, pois continuam divulgando os produtos por meio de publicidade muitas vezes inadequada e enganosa, estabel ecendo conflitos permanentes entre empresas, governo e sociedade. 0 fenômeno aqui identificado vem reforçar os argumentos propostos pela bioética de intervenção ${ }^{9,12}$, de que é moralmente legítima a regulação governamental em áreas públicas sensíveis, como éo caso da propaganda de medicamentos, uma vez que, com essa medida, se está beneficiando a sociedade como um todo e garantindo melhores conseqüências coletivas.

Schramm e Kottow ${ }^{26}$ acreditam ser viável a implementação de políticas embasadas "num princípio de proteção que seria mais adequado aos propósitos de uma ética para a saúde pública, permitindo identificar claramente os objetivos e atores implicados em uma implementação de políticas estatais moralmente corretas e pragmaticamente mais efetivas".

Por todas as razões até aqui expostas, a publicação da RDC número 102/00 deve ser vista como um importante progresso no controle da propaganda e publicidade de medicamentos no Brasil. Sua publicação é um marco histórico de fundamental importância para a consolidação da atuação da Agência Nacional de Vigilância Sanitária como elemento articulador das políticas públicas de intervenção e proteção da sociedade brasileira global mente considerada.

É do rigor e do comprometimento do Estado na implementação de políticas de educação, normatização e fiscal ização que dependerá o futuro da publicidade de medicamentos no país, principalmenteno que diz respeito à prescrição com base nos requisitos da Organização Mundial da Saúde (OMS) e no consumo racional pela população.

Contudo, apesar da evolução proporcionada pela RDC número 102/00 e da intensificação das ações fiscalizadoras da Anvisa, é indispensável que novas medidas concretas com base na ética da proteção (para beneficiar a sociedade) e na bioética de intervenção (que justifica o papel qualitativo e controlador do Estado) sejam tomadas futuramente. A propaganda de medicamentos, no Brasil, não pode prescindir de um controle absolutamente rigoroso paraqueo país, com relação a esse aspecto específico, possa responder adequadamente aos requisitos indispensáveis para uma verdadeira democracia participativa do Século XXI.

\section{Colaboradores}

MJ Delgado Fagundes trabalhou na aplicação dos questionários, sel eção e análise das peças publicitárias, pesquisa bibliográfica, concepção e redação do trabalho. M GA Soares atuou na aplicação dos questionários e concepção do trabalho. NM Diniz eJR Pires trabalharam na pesquisa bibliográfica e na redação final. V Garrafa atuou em todas etapas como orientador da pesquisa. 


\section{Referências}

1. Massera APD, Camargo JAS, Silva LRFJ. 0 controle do comportamento privado para fins públicos: a monitoração de propaganda de medicamentos no Brasil [monografia de curso de especialização]. Brasília: Faculdade de Ciências da Saúde da Universidade de Brasília; 2002.

2. Nascimento AC. A persistirem os sintomas, o médico deverá ser consultado - isto é regulamentação? [dissertação]. Rio de Janeiro (RJ): Instituto de M edicina Social da UERJ; 2003.

3. Barros JAC. Propagandas de medicamentos: atentado à saúde? São Paulo: Hucitec-SOBRAVIME; 1995.

4. Avorn J, Chen M. Scientific versus commercial sources of influence on the prescribing behavior of physicians. American Journal of M edicine 1982; 73:4-8.

5. Lexchin J. Interactions between physicians and the pharmaceutical industry: what does the literature say? Canadian Medical Association Journal 1993; 149:1.

6. M ansfield P. Drug advertising affects your prescribing. Australian Prescriber 1996; 19:103.

7. Wade VA, M ansfield PR, M CD onald PJ. Drug companies - evidence to justify advertising. Lancet 1989; II (8674):1.261-263.

8. Heineck i, Gallina sm, Silva T, Pizzol FD, Schenkel EP. Análise da publicidade de medicamentos veiculadas em rádios do RS. Cad. Saúde Pública 1998; 14(1):193-198.

9. Garrafa V, Porto D. Intervention bioethics: a proposal for peripheral countries in a context of power and injustice. Bioethics 2003; 17(5-6):399-416.

10. Barros JAC. One more case of the double standard: discrepancies between information provided to Brazilian and American physicians. Pharmaco - Epidemiology and Drug Safety 2000; 9:281-287.

11. Garrafa V. Inclusão social no contexto político da bioética. Rev Bras Bioética 2005; 1(2): 122-132.

12. Garrafa V, Porto D. Bioética, poder e injustiça: por uma ética de intervenção. In: Garrafa V; Pessini L, organizadores. Bioética: poder e injustiça. São PauIo: Loyola/Sociedade Brasileira de Bioética; 2003. p. $35-44$

13. Selli L, Garrafa V. Bioética, solidariedade crítica e voluntariado orgânico. Rev Saúde Pública 2005; 39(3):473-478.

14. Fortes PAC 2003. Como priorizar recursos escassos em países em desenvolvimento, pp. 103 -114. In: Garrafa V, Pessini L, organizadores. Bioética: poder e injustiça. São Paulo: Loyola/Sociedade Brasileira de Bioética; 2003. p. 103-114.
15. Sen, A. Sobre ética e economia. São Paulo: Schwartz; 1999.

16. Sass, HM. Promover a educação em saúde para enfrentar a doença e a vulnerabilidade. In: Garrafa V, Pessini L, organizadores. Bioética: poder e injustiça. São Paulo: Loyola/Sociedade Brasileira de Bioética; 2003. p. 79-86.

17. Kottow MH 2003. Comentários sobre bioética vulnerabilidade e proteção. In: Garrafa V, Pessini L, organizadores. Bioética: poder e injustiça. São PauIo: Loyola/ Sociedade Brasileira de Bioética; 2003. p. 71-78.

18. Schramm, FR. Información y manipulación: ¿cómo proteger los seres vivos vulnerados? La propuesta de la bioética de la protección. Rev Bras Bioética 2005; 1(1):18-27.

19. Lima MA, Petrovick PR. Avaliação da publicidade visual de medicamentos em estabelecimentos farmacêuticos de Porto Alegre-RS. Rev. Farmácia Brasileira 2003; 3(36).

20. Santi V. M edicamentos: verso e reverso da propaganda. Ponta Grossa: Editora Universidade Estadual de Ponta Grossa; 1999.

21. Megginson LC, Mosley, DC, Pietri PH Jr. Administrando com ética e responsabilidade social. In: Megginson LC. Administração: conceitos e aplicações. 4a ed. São Paulo: Harbra; 1998. p. 91-118.

22. Barros JAC. Políticas farmacêuticas: a serviço dos interesses da saúde? Brasília: UNESCO; 2004.

23. Pizzol FD, Silva $T$ da \& Schenkel EP. Análise da adequação das propagandas de medicamentos dirigidas à categoria médica, no sul do Brasil. Cad. Saúde Pública 1998; 14(1):85-91.

24. Silva VS, Hoelfer R, M oraes LB. Avaliação das propagandas de medicamentos distribuídas para a classe médica de Brasília. 1999 [acessado 2003 Nov 05]. Disponível em: http://www.cff.org.br/cebrim/

25. Anvisa. Propaganda de M edicamentos - dados parciais. 2003 [acessado 2003 Out 20]. Disponível em: http://www.anvisa.gov.br

26. Schramm FR \& Kottow M. Principios bioéticos en salud pública: limitaciones y propuestas. Cad Saúde Pública, 17 (4): 949-956.

Artigo apresentado em 25/04/2005

Aprovado em 10/01/2006

Versão final apresentada em 23/01/2006 